\title{
Breach and Fulfillment of the Psychological Contract: Understanding Behavior in the Context of Time
}

\author{
Paata Brekashvili
}

Ilia State University

\begin{abstract}
This paper explores the role of time context in psychological contracts. The study aims to expand the understanding of psychological contract breach and fulfillment through proposing the role of time as contextual variable in the process of exchange relationship between employee and employer. It is argued that contract breach can occur not only by deficient and excess inducements, but also by deviation from promised time such as early and late delivery of promised inducements. Based on prior work, three types of delivered inducements are analyzed: economic, socio-emotional and developmental. With different types and levels of employers' inducements employees' levels of satisfaction are predicted. Employee's achievement orientation is proposed to moderate relationship between delivered inducements and employee satisfaction. Beside number of different propositions it is predicted that, employee's satisfaction will be positively related with employer's early-deficient inducements, when employees fall in low achievement orientation category. Moreover, employee's satisfaction is also proposed to positively relate with late-excess inducements when employees fall in high achievement orientation category.
\end{abstract}

Keywords: Psychological contract; Time context; Breach; Inducement; Job satisfaction 